University of Nebraska - Lincoln

DigitalCommons@University of Nebraska - Lincoln

To Improve the Academy

Professional and Organizational Development Network in Higher Education

1996

Experiences of Newly Hired Faculty

Robert J. Menges

Follow this and additional works at: https://digitalcommons.unl.edu/podimproveacad

Part of the Higher Education Administration Commons

Menges, Robert J., "Experiences of Newly Hired Faculty" (1996). To Improve the Academy. 360.

https://digitalcommons.unl.edu/podimproveacad/360

This Article is brought to you for free and open access by the Professional and Organizational Development Network in Higher Education at DigitalCommons@University of Nebraska - Lincoln. It has been accepted for inclusion in To Improve the Academy by an authorized administrator of DigitalCommons@University of Nebraska - Lincoln. 
Menges, R. J. (1996). Experiences of Newly Hired Faculty. In L. Richlin (Ed.), To Improve the Academy, Vol. 15 (pp. 169-182). Stillwater, OK: New Forums Press and the Professional and Organizational Development Network in Higher Education. Key words: New Faculty, Faculty Development Role, New Faculty Programs.

\section{Experiences of Newly Hired Faculty}

\section{Robert J. Menges}

Northwestem University

Faculty experiences during the first three years in a new job were investigated by following new hires at five colleges and universities. Their initial years are characterized by stress, dilemmas about how to allocate time to competing responsibilities, uncertainty about what is expected of them, and dissatisfaction with feedback about their progress. Faculty development offices can promote more enlightened policies and practices to help ease faculty transition into a new job.

Moving from one job to another is rarely easy, and difficulties are compounded when the new position requires geographical relocation, calls for new skills, and entails new responsibilities. All this is true when academics, particularly junior academics, assume new positions.

The transition may be from graduate student or adjunct status to a tenure-track appointment. It may mean moving from state to state or across the country. It may involve settling children in school and finding employment for other adults in the family. Even those who have previous experience as full time academics feel tested when they move into a new job at a new college or university. 
To learn more about how faculty experience these transitions, we undertook a three-year study of newly hired academics, giving most attention to those in the junior ranks.

\section{Some Things We know About Junior Faculty}

Our knowledge about the experiences of junior faculty has heretofore been based largely on small-scale, short-term research. Most previous studies (see, for example, Boice, 1992, and Sorcinelli \& Austin, 1992) were conducted at only one institution or at only one point in time. Few investigations extend beyond the first year of employment.

Despite these limitations, available research about new and junior faculty yields findings from which several themes can be discerned. As I have written elsewhere (Menges, 1994), this research reveals five problematic features of junior faculty life. First, anxiety is high for junior faculty. This is no longer anxiety about finding a job; it has now become anxiety about surviving in the job. Second, junior faculty feel tremendous pressure from obligations that compete for their time and energy. Often they find themselves taking time from important professional activities and from meaningful personal pursuits in order to meet demands that seem more urgent, usually the demands of teaching. Third, junior faculty report a sense of isolation, finding fewer connections with colleagues than they expected to have and than they would like to have. Fourth, stress from professional matters overflows into non-work areas, creating tension in families and other personal relationships. Finally, new and junior faculty experience dissonance about the rewards they receive for their work. Although the great majority of their time is spent in teaching-related activities, faculty, at least those at most four-year institutions, soon learn that compensation and advancement are strongly dependent on achievements in research and scholarship.

\section{The New Faculty Project}

The program of research on faculty at the National Center on Postsecondary Teaching, Learning, and Assessment conducted the 
New Faculty Project to better understand and enhance the experiences of new and junior faculty.

For the research to be methodologically sound required focusing . on several types of institutions, gathering data over a period of several years, and utilizing both quantifiable data from large-scale surveys and qualitative information from interviews and intensive case studies. Further, we realized that relevance of our findings for the policies and practices of individual institutions depends upon contextual validity. Consequently, we discussed preliminary findings with those who participated in the study before preparing specific suggestions and recommendations for individual participating colleges and universities.

The New Faculty Project ultimately included five colleges and universities and followed faculty hired at those institutions in 1991 and 1992 over the first three years of their employment.

We secured the cooperation of academic administrators at five institutions: a research university, a comprehensive university, a community college district, and two liberal arts colleges (we differentiated the latter according to their location, calling one "rural" and the other "urban). They provided lists of faculty hired into full time tenure-track positions for fall 1991 and 1992. Surveys were sent to those new hires at approximately the middle of the fall term in their first, second, and third years on the job. We excluded faculty in professional and applied fields if they did not have counterparts at all of the institutions. Each fall during those years, we also conducted face-to-face interviews with a sub-group of the 1991 new hires drawn from the arts and sciences.

Although new hires at all ranks were included in the study, this report is limited to new hires below the rank of full professor.

\section{Who Was Surveyed?}

The year of 1991 was a good year for hiring at all five institutions. Surveys were sent to 225 faculty who met the researchers' criteria (persons hired into full time, tenure track positions). Of these, 51 percent are female and 24 percent are faculty of color. By fall 1992, the impact of adverse economic conditions had been felt across higher education, and hiring at these institutions was reduced to a total of 123 
persons. Of these, 50 percent are female and 23 percent are faculty of color.

\section{Who Responded?}

As usual for research of this kind, not everyone returned our lengthy 16 page survey. At the research university, for example, it was completed in year one by 70 percent, by 53 percent in year two, and by 44 percent in year three; consequently, when we report changes over time, the number of faculty at the research university is a maximum of 49 continuing respondents. Response rates at other institutions were similar. Findings reported here are based on continuing respondents from each institution, a maximum of 49 community college faculty, 41 comprehensive university faculty, 49 research university faculty, 8 from the rural liberal arts college, and 11 from the urban liberal arts college. When those who left their institution during the period of the study are taken into account and when the small number of full professors is excluded, continuing respondents approximate 50 percent of eligible participants.

Interviews were held with only 1991 new hires. These totaled 91 in 1991, 89 in 1992, and 79 in 1993. Interviews averaged about one hour. Nearly all faculty who were interviewed also completed surveys in all three years.

\section{Are Respondents Representative?}

We investigated whether returns are biased by gender, and found that they are not. Like the surveyed group, respondents include about as many males as females. Thinking that males and females might differ on some variables, we searched diligently for gender differences. None were uncovered within any of the participating institutions. Likewise, we found no difference related to marital status or the presence of children. Only when responses are combined across all institutions do some gender-related trends appear. (See, for example, Menges \& Trautvetter, 1993.)

To determine whether faculty who completed the survey in all three years differ from faculty who did not, we compared responses to key items for those who returned surveys in the first year, on the 
one hand, and those who responded in all three years, on the other. No significant differences were found for such variables as job satisfac-. tion and stress. We concluded that respondents are adequately representative.

Nevertheless these findings are limited because of the modest numbers available for analysis. At any single institution, numbers are too small for comparisons across departments or colleges, and faculty of color are too few for ethnic comparisons. The study is best regarded as a set of case descriptions. Findings must be interpreted in light of circumstances peculiar to each institution and to the individuals and departments in them.

\section{Some Key Findings}

This report summarizes findings about four topics: faculty stress, time allocation, job expectations, and the faculty evaluation process. These findings derive from both survey and interview responses and are further influenced by conversations with faculty and administrators during visits to the participating institutions when we discussed preliminary findings.

\section{Figure 1}

\section{Work-Related Stress Across Institutions}

Indicate the extent to which each of the following has been a source of stress for you during the past twelve months.

\section{Year 1}

¿Committee \& Teaching a Research oReview

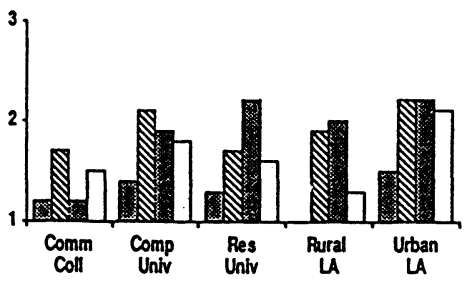

Year 3

sCommittee o Teaching a Research oReview

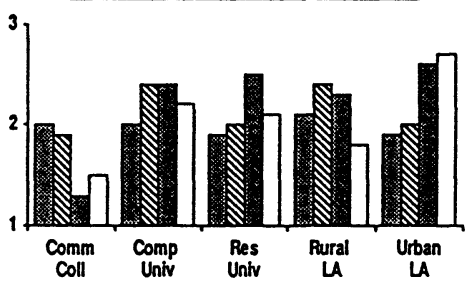




\section{Stress}

We asked faculty about stress they experienced from both work and non-work sources. Work-related sources of stress include committee participation and faculty meetings, teaching load, research and publishing demands, and review and promotion processes. Non-work sources include managing household responsibilities and lack of personal time.

Regarding work-related stress in year one, we found it to be lowest overall at the community college (see Figure 1). Of the four-year institutions, stress from teaching load was lowest at the research university, although stress from research and publishing demands was relatively high at that institution.

By year three, trends at all institutions are toward greater stress (see Figure 1). Stress from teaching load is particularly high at the comprehensive university and at one of the liberal arts colleges. Stress from research and publishing demands remains high at the research university and at the other liberal arts college.

Stress from non-work sources is moderate in year one and fairly similar across institutions. Trends by year three are upwards, with especially high stress from lack of personal time at the research university and at one of the liberal arts colleges.

Figure 2

\section{Time Allocation Across Institutions: Actual}

During the current term, what percent of time are you giving to teaching, professional growth, research and other scholarly activities, and service in a typical week?

Year 1

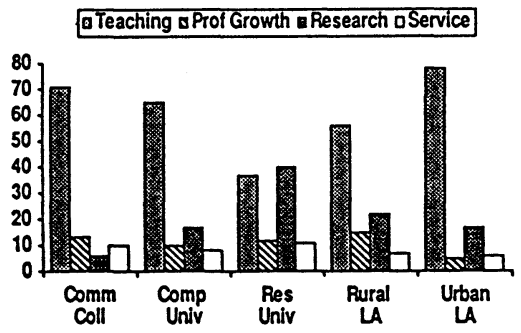

Year 3

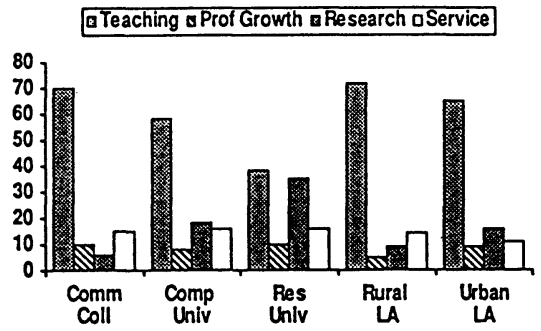




\section{Time Allocation}

We asked faculty about the proportion of time they allocate to each of four domains of work: teaching, professional growth, research and other creative scholarly activities, and service.

In year one, teaching typically accounts for about two-thirds of faculty time, except at the research university where time for teaching and for research are similar (see Figure 2). In general, time allocation seems most appropriate at the research university and at the community college, in that it is consistent with the missions of those institutions. The research university balances time for teaching fairly closely with time for research. At the community college, which has no expectation of scholarly publication, time for teaching averages about 70 percent in both years one and three.

By year three, time devoted to service has increased at all institutions. The great majority of time, except at the research university, still goes to teaching.

We also asked faculty how they would prefer to allocate their time and how they think the institution expects them to allocate it. In most cases, preferences and perceived expectations are similar and fairly constant over the three years. Faculty typically believe they are devoting more time to teaching than the institution expects (see Figure 3 in comparison with Figure 2). They would prefer to move toward a balance by increasing time for scholarly work and slightly decreasing

Figure 3

\section{Time Allocation Across Institutions: Expected}

How do you think the institution expects you to spend your time?

Year 1

B Teaching \& Prol Growth a Research a Service

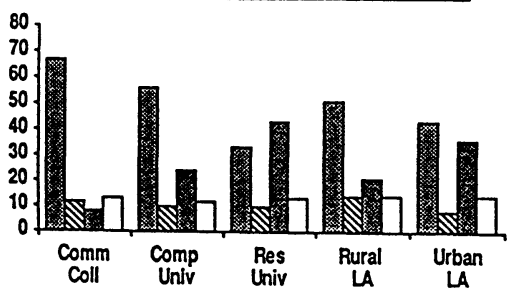

Year 3

G Teaching \& Prof Growth a Research aService

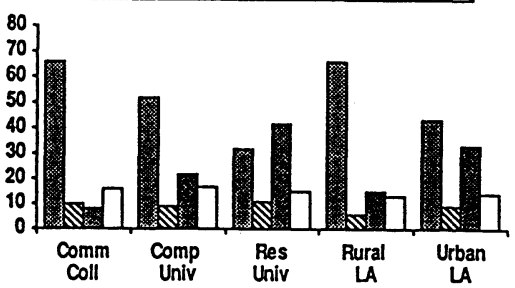


time for teaching. We also found that the greater the discrepancy between how faculty allocate their time and how they perceive the institution expects them to allocate it, the more stress they report.

\section{Job Expectations}

During interviews in years two and three, we asked faculty about the clarity of expectations for their work (on a scale of 1 to 10). Individual responses were highly variable, ranging all the way from 1 to 10 . On average, faculty reported that expectations were no more clear in year three than they were in year two (see Figure 4).

Figure 4

\section{Clarity of Expectations}

On a scale from one to ten, how clear are expectations for your work here? (1 is low clarity and 10 is high) The chart shows median responses.

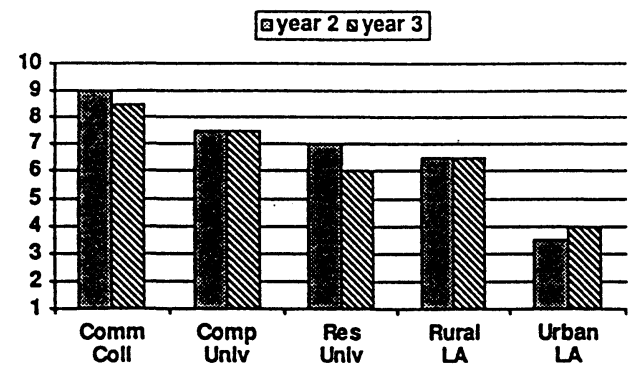

When we asked for examples of areas where expectations are clear and areas where they are not clear, expectations about teaching were most frequently mentioned as clear. (Because clarity of expectations was relatively high at the community college, comments are quoted only from the four-year institutions.)

- Expectations for teaching are very clear. The university expects you to be devoted to students. Teaching is very important, including out-of-class contact with students, advising, and so on. (comprehensive university)

- Teaching. The teaching load is very clear. I know how many courses per year I'm expected to teach. I'm expected to keep 
enrollment up and do a good job so the department gets money. It's a cost analysis thing; the more students who take courses in this department, the more money the department gets. (research university)

- What's clear is that if you're totally awesome as a teacher, it's great. (rural liberal arts)

Others, especially at the research university, found expectations about scholarship to be clear.

- What's clear? That's easy. Scholarship. To continue publishing at an even rate and high quality. (research university)

Expectations about both teaching and scholarship are seen as less clear when the focus shifts from "what" to "how much" or "how good."

- Teaching is very clear. Nothing unusual. Quality teaching. But I wonder how good is good enough. There's no rule about that. (comprehensive university)

- I was told when I was hired, to get tenure you must "increase your visibility and standing in the profession." It's like reading tea leaves. What this means was never made clear. (urban liberal arts)

- In research, it's not so clear how to judge quality of work versus quantity. (research university)

And some faculty hear mixed messages.

- From the administration, expectations are very clear. From the faculty, it is less clear. The department chair is not to the point about a lot of issues. Expectations from the students are even less clear. (rural liberal arts)

Although diversity across institutions was considerable, there was also a great deal of diversity within institutions. What is clear to one person may not be clear to another, even within the same department, and especially when judgments are made using different criteria (such as quality versus quantity). 


\section{The Faculty Review Process}

When asked in year three about the performance evaluations they had undergone, some faculty noted that the review was reassuring and clarifying.

- For the first time, I was told that they liked what I was doing and that I was meeting expectations. (research university)

- They are supportive, encouraging. It's good to get colleague's affirmation. (community college)

- The evaluation clarified a lot. I know what the "scholarly academic thing" means. (comprehensive university)

On balance, however, more comments about the review process were negative then positive, most commonly noting the absence of corrective feedback.

- It was not very helpful. All that resulted was that "everything's okay." That's absolutely no help to me. (urban liberal arts)

- There was little feedback or impact on teaching. Very little criticism on that. I would have liked to see more of teaching criticism. (research university)

- People are too nice and kind, so they don't give suggestions that might help people to improve. (community college)

Nearly everyone was concerned about the time and effort required by the review.

- What is lamentable is the stress everyone goes through. It is a hurdle. It's not set up for you, it's set up for them. (urban liberal arts)

That person saw the review as a hurdle. Others found their own expressions for conveying the review experience.

- It's like doing laundry - something that takes up time, and it gets in my way, but I accept that it has to be done. (community college)

- Like taking medicine. (comprehensive university)

- It's a hoop I have to jump through. (rural liberal arts)

- Just a pain in the butt. (comprehensive university) 


\section{For Discussion and Action}

Some of these findings have obvious implications. At one of the liberal arts colleges, for example, data revealed discrepancies between how junior faculty and institutional leaders perceived expectations for faculty work. Junior faculty noted that after their third year reviews, which emphasize teaching, they may apply for a one-term leave. Thus, they reasoned that they could spend the overwhelming proportion of their time meeting the daily demands of teaching and use the leave as a time to catch up with the scholarly expectations for tenure. Administrators and senior faculty have something different in mind. They recognize that scholarship must be a high priority from the very beginning of employment. They see the purpose of the leave as more for renewal than for catching up. Here is an obvious point for discussion and action.

Each of the sections above raises questions that institutional leaders should pursue.

1. Stress. Stress is an issue for all professionals and no less so for academics. For faculty in their first three years, it sometimes seems that work is deliberately arranged to be highly stressful. Institutions should consider these questions:

- To what extent is stress from work-related sources dysfunctional when it increases from year to year?

- How can the consequences of stress be evaluated (consequences for faculty vitality, for student learning and satisfaction, for the reputation of the institution)?

- If stress is more acute than intended, what steps to reduce it are appropriate and effective?

2. Discrepancies in time allocation. Discrepancies between actual, preferred, and expected allocation of time are correlated with stress. Institutional leaders should reflect on causes of these discrepancies. Among possible causes are inappropriate expectations, poorly communicated or misunderstood expectations, faculty disregard of expectations, or some combination of these. How can the institution determine which causes apply?

- Are expectations for time use appropriate?

- Are expectations poorly articulated and communicated? 
- Do faculty fail to understand the communications about priorities and expectations?

- Do faculty knowingly contradict what they understand is expected?

3. Evaluation and feedback. Regarding evaluation of faculty performance, institutions need to consider these questions:

- Is it institutional policy that review procedures and criteria be obscure to new faculty? If not, how can they be clarified?

- If teaching effectiveness is seriously examined in the review process, what documentation should be presented to demonstrate the scholarly aspects of teaching? What documentation should be expected from all candidates and what documentation might differ by department or according to the level of the review?

Regarding feedback, institutions should consider these questions:

- How can the purpose of reviews come to be seen as assisting already productive faculty rather than as identifying faculty who are not likely to succeed?

- How can reviews result in feedback that is detailed, diagnostic, and constructive?

- What are the roles of department chairs and mentors in providing feedback to faculty, and how can they develop the skills needed to provide feedback effectively?

- How can faculty themselves be assisted to become more effective in seeking feedback about their work?

4. Criteria for promotion and tenure. Some institutions in the study are apparently attempting to raise academic standards and prestige by emphasizing faculty research and related scholarly productivity without commensurate reduction (or only little reduction) in teaching expectations.

- What are the consequences for faculty of these changes in expectations and standards?

- What are the consequences for student learning? For student experiences with faculty?

- What are the consequences for relationships between veteran faculty and newer faculty? 


\section{Conclusion}

In conclusion, I recommend that faculty development offices gather local data on these topics. It is then very productive to bring new hires together with senior faculty and administrators a) to discuss the data and $b$ ) to develop policies and practices that are supportive of the needs of junior faculty.

\section{References}

Boice, R. (1992). The new faculty member. San Francisco: Jossey-Bass.

Menges, R.J. (1994). Preparing new faculty for the future. Thought \& Action, 10(2), 81-95.

Menges, R.J., \& Trautvetter, L.C. (April, 1993). Socialization of newly hired female faculty across types of institutions and disciplines. Paper presented at the annual meeting of the American Educational Research Association, Atlanta, GA.

Sorcinelli, M.D., \& Austin, A.E. (Eds.). (1992). Developing new and junior faculty. New Directions for Teaching and Learning, No. 50. San Francisco: Jossey Bass.

Contact:

Robert J. Menges

Center for Teaching Professions

Northwestem University

2115 North Campus Drive

Evanston, IL 60208-2610 USA

(708) 467-1746

r_menges@nwu.edu

Robert J. Menges is professor of education and social policy at Northwestern University and a senior researcher with the National Center on Post-secondary Teaching, Learning and Assessment. His scores of publications include influential research reviews about student evaluation of teaching and effectiveness of faculty development programs. Two of his recent co-edited books include Teaching on Solid Ground: Using Scholarship to Improve Practice and Instructional Consultation in Higher Education: Handbook of Principles and Practices. In 1991, Menges received the W.K. McKeachie Achievement Award for his contributions to the development and evaluation of faculty in post-secondary education. In 1992, he received the Amoco Foundation Faculty Award from Northwestern University.

This research was conducted by the National Center on Postsecondary Teaching, Learning, and Assessment, an educational research and development center supported by the Office of Educational Research and Improvement, US Department of Education. NCTLA is a consortium housed at the Pennsylvania State University and includes Northwestern University, University 
of Illinois at Chicago, Syracuse University, Arizona State University, and University of Southem California. Findings and opinions expressed in this report do not nocessarily reflect the positions and policies of these agencies and institutions. 